\title{
A Comparative Analysis of the Anxiety in Offenders of the Law Based on Structural Equational Models
}

\author{
Catalina Quintero-López ${ }^{1}$, Víctor Daniel Gil-Vera ${ }^{1}$, \\ Alejandra Bustamante-Hernández ${ }^{1} \&$ Luis Eduardo De Ángel-Martínez ${ }^{1}$ \\ ${ }^{1}$ Universidad Católica Luis Amigó, NBA Research Group, Neurocognitive Profiles and Psychology Line, \\ Faculty of Psychology, Medellín, Colombia \\ Correspondence: Catalina Quintero López, Department of Psychology, Universidad Católica Luis Amigó, \\ Colombia.
}

Received: December 6, 2019

Accepted: January 28, 2020

Online Published: January 29, 2020

doi:10.5539/mas.v14n2p65

URL: https://doi.org/10.5539/mas.v14n2p65

\begin{abstract}
Anxiety affects men and women and have a negative impact on their lives. This paper presents two structural equation models (SEM) to evaluate the variables (physiological and cognitive), that most influenced the anxiety in men and women offenders of the law. Was used a representative sample of 60 offenders of the law (30 mens and 30 womens) of the Specialized Attention Center (SAC) "Carlos Lleras Restrepo" in Medellin, Colombia with diagnosis of Antisocial Personality Disorder (APD). The results of Bartlett's and KMO tests, indicated that the factorial analysis is adequate, all the constructs are statistically significant. The goodness-of-fit test indicated that the model fits well with the data. This paper concludes that, of the two constructs considered: physiological and cognition, in the men the construct that most influences the latent variable physiological are the "Palpitations or tachycardia". The construct that most influences the latent variable cognitive is the "a feeling of instability". In the women, the construct that most influences the latent variable physiological is the "dizziness or vertigo". The construct that most influences the latent variable cognitive is "be afraid".
\end{abstract}

Keywords: anxiety, SEMs, brain, offenders of the law, cognition

\section{Introduction}

Anxiety is a body's response to situations limits, which is characterized by a sensation of mild distress or fear, and the emergence of rapid heart rate and breathing, sweating or feeling of looseness. This is normal and can even help you prepare to deal with complicated situations (Newby et al., 2019). When the body and mind react to danger or threat, a person feels physical sensations of anxiety - things like a faster heartbeat and breathing, muscle tension, palms sweat, a discomfort in the stomach and trembling in hands and legs. A sample of 30 men and 30 women offenders of the law of the Specialized Attention Center (SAC) "Carlos Lleras Restrepo" in Medellin, Colombia with diagnosis of APD, completed a specialized questionnaire. All authorized access to their offender records. The problem that the paper intends to address was to analyzed why the therapies and treatments used for anxiety control in Specialized Attention Centers (SAC) don't have the same effect on men and women. The objective of this research was to develop two structural equation models (SEM) to evaluate the variables (physiological and cognitive), that most influenced the anxiety in mens and womens offenders of the law. This research first presents a brief contextualization of the structural equation models (SEM), the methodology, results obtained from the models and their interpretation. Finally, it is concluded. This paper concludes that, of the two constructs considered: physiological and cognition, the "Palpitations or tachycardia" and the "dizziness or vertigo" are the two constructs that more influenced the latent variable physiological in men and women respectively. The "feeling going to faint" and "be afraid" are the two constructs that more influenced the latent variable cognitive in men and women respectively. This research shows that show that there is a physiological and cognitive difference between men and women when they have anxiety, this is the added value that this research brings to the existing academic literature.

\section{Literature Review}

The anxiety is part of the response of the body of "flee or fight". They are caused by an increase in the production of adrenaline and other chemicals that prepare the body to quickly escape from danger. They may 
occur as mild symptoms or extreme (Buckner, Lewis, Terlecki, Albery, \& Moss, 2019). Individuals with antisocial personality disorder often break the laws and become criminals. Can lie, violent or behave impulsively, and have problems with drug and alcohol use. Due to these characteristics, people with this disorder typically cannot fulfill their responsibilities related to family, work or school (Mullarkey \& Schleider, 2020). There are various types of anxiety disorders: for example, generalized anxiety disorder, social anxiety disorder, generalized anxiety disorder Panic disorder or obsessive-compulsive disorder (Fox, Russo, \& Georgiou, 2005; Hirshfeld-Becker et al., 2007). Anxiety symptomatology is frequently reported in offenders and prisoners, and the prevalence of anxiety disorder is estimated at around $40 \%$ (Keen, Adams, Simpson, Den Houting, \& Roberts J., 2019). To affect mood, thinking, and behavior of the person, the presence of an anxiety disorder can make everyday life at home, at work or school, as well as social relations (Vertue, 2003). Most cases of anxiety disorders can be treated satisfactorily by health professionals and mental health properly trained. The problems experienced by young prisoners is the fear of exaggeration and anxiety unacceptable in the social environment, Depression and anxiety are most strongly associated with low levels of perceived support (Regehr, Carey, Wagner, Alden, Buys, Corneil, White, 2019). Several studies have shown that both behavioral therapy such as cognitive and behavioral therapy (CBT) can be very effective in treating anxiety disorders. The psychologists use the CBT to help patients identify and learn to control the factors that contribute to their anxiety (American Psychiatric Association, 2000; Kinner et al., 2005). Prisoners with neurodevelopmental difficulties showed greater vulnerability to anxiety and thoughts of suicide and suicide-related behaviours than other prisoners. Accordingly, we recommend routine early screening across the criminal justice system for any neurodevelopmental difficulties to inform decision-making on the most appropriate disposal and support.

\section{Method}

Structural equation models are a family of multivariant statistical models which allow us to estimate the effect and the relationships among multiple variables. Structural equation models were born out of the need for greater flexibility to the regression models. Are less restrictive than the regression models by the fact of allowing to include measurement errors in both the criterion (dependent) variables as in the predictive variables (independent) (Ruiz, Pardo, \& San Martín, 2010). Mathematically, these models are more complex to estimate what other multivariate models such as regression or exploratory factor analysis (Mclntosh \& Gonzalez - Lima, 1994; Price, Laird, Fox, \& Ingham, 2009). The great advantage of this type of models is that they allow to propose the type and direction of relationships that are expected to find among the various variables contained in it, for having to subsequently to estimate the parameters that are specified by the relations proposals at the theoretical level (Pruttiakaravanich \& Songsiri, 2020). We analyzed the relationships between twenty-one constructs and two latent variables (physiological and cognitive). Was used a database that met the responses from a survey of the "Anxiety Questionnaire". The survey was applied to a representative sample of 60 offenders of the law in a SAC in Medellin, Colombia. The sample was selected considering a margin of error between $5 \%$ and $10 \%$ and a confidence level of $90 \%$, the size of the population was 60 men and 57 women offenders of the law with APD (equation 1). We used multivariate statistical techniques; regression and factor analysis in the statistical software STATA 16.

$$
n=\frac{Z^{2}\left(p^{*} q\right)}{e^{2}+\frac{\left(Z^{2}\left(p^{*} q\right)\right)}{N}}
$$

Where: $n$ : amount of people, $p$ : population with the characteristic, $Z$ : confidence, $q$ : population without the characteristic, e: error level willing to commit, $N$ : population size. Table 1, presents the description of each variable used in the development of the model (SEM).

\section{Results}

Any KMO is below 0.5 , which is why it can be said that factor analysis is valid. The evidence of sphericity rejected at any level of significance considering the results of the Bartlett's sphericity test, the matrix of correlations is not an identity matrix. 
Table 1. Men's Anxiety Questionnaire results

\begin{tabular}{|c|c|c|c|c|c|c|}
\hline \multirow[t]{2}{*}{ Construct } & \multirow[t]{2}{*}{ Description } & \multirow[t]{2}{*}{ Variable } & \multirow{2}{*}{$\begin{array}{c}\text { Measurement } \\
\text { of sample } \\
\text { adequacy of } \\
\text { Kaiser - Meyer } \\
\text { - Olkin (KMO) }\end{array}$} & \multirow[t]{2}{*}{$\begin{array}{c}\text { Approximate } \\
\text { Chi square }\end{array}$} & \multicolumn{2}{|c|}{$\begin{array}{c}\text { Bartlett's } \\
\text { sphericity } \\
\text { test }\end{array}$} \\
\hline & & & & & $\mathrm{gl}$ & sig \\
\hline \multirow{11}{*}{ Physiological } & Tingling or numbness & A1 &, 522 & 24,654 & 3 &, 000 \\
\hline & Weakness in the legs & $\mathrm{A} 2$ &, 501 & 23,987 & 1 &, 000 \\
\hline & Inability to relax & A3 &, 598 & 21,411 & 1 &, 000 \\
\hline & Dizziness or vertigo & A4 &, 554 & 22,546 & 1 &, 000 \\
\hline & Palpitations or tachycardia & A5 &, 565 & 26,879 & 3 &, 000 \\
\hline & Nervousness & A6 &, 628 & 115,213 & 1 &, 000 \\
\hline & Trembling of hands & A7 &, 596 & 27,654 & 1 &, 000 \\
\hline & $\begin{array}{l}\text { Generalized tremor or } \\
\text { shaking }\end{array}$ & A8 &, 565 & 29,874 & 1 &, 000 \\
\hline & Difficulty breathing & A9 &, 545 & 116,547 & 3 &, 000 \\
\hline & $\begin{array}{l}\text { Indigestion or discomfort in } \\
\text { the abdomen }\end{array}$ & A 10 &, 522 & 35,684 & 1 &, 000 \\
\hline & Facial Blush & A11 &, 501 & 24,654 & 1 &, 000 \\
\hline \multirow{10}{*}{ Cognitive } & Sweating & A 12 &, 598 & 23,987 & 1 &, 000 \\
\hline & Heat sensation & A13 &, 554 & 21,411 & 3 &, 000 \\
\hline & $\begin{array}{l}\text { Fear for the worst to } \\
\text { happen }\end{array}$ & A14 &, 596 & 22,546 & 3 &, 000 \\
\hline & A feeling of instability & A15 &, 565 & 24,654 & 1 &, 000 \\
\hline & Feeling of being terrified & A16 &, 545 & 23,987 & 1 &, 000 \\
\hline & Feeling of choking & A17 & ,678 & 21,411 & 1 &, 000 \\
\hline & Fear of losing control & A18 &, 532 & 22,546 & 3 &, 000 \\
\hline & Fear of dying & A19 &, 523 & 26,879 & 1 &, 000 \\
\hline & Be afraid & A20 &, 541 & 115,213 & 1 &, 000 \\
\hline & Feeling going to faint & A21 &, 514 & 27,654 & 1 &, 000 \\
\hline
\end{tabular}

Source: authors' elaboration 
Table 2. Women's Anxiety Questionnaire results

\begin{tabular}{|c|c|c|c|c|c|c|}
\hline Construct & Description & Variable & $\begin{array}{l}\text { Measurement } \\
\text { of sample } \\
\text { adequacy of } \\
\text { Kaiser - Meyer } \\
\text { - Olkin (KMO) }\end{array}$ & $\begin{array}{l}\text { Approximate } \\
\text { Chi square }\end{array}$ & $\begin{array}{r}\mathrm{Ba} \\
\mathrm{sph}\end{array}$ & $\begin{array}{l}\text { ett's } \\
\text { icity } \\
\text { sig }\end{array}$ \\
\hline \multirow{12}{*}{ Physiological } & Tingling or numbness & A1 & ,598 & 115,897 & 3 & ,000 \\
\hline & Weakness in the legs & $\mathrm{A} 2$ &, 554 & 263,874 & 1 &, 000 \\
\hline & Inability to relax & $\mathrm{A} 3$ &, 565 & 24,654 & 1 &, 000 \\
\hline & Dizziness or vertigo & A4 & ,628 & 23,987 & 1 &, 000 \\
\hline & Palpitations or tachycardia & A5 &, 596 & 21,411 & 3 &, 000 \\
\hline & Nervousness & A6 &, 565 & 22,546 & 1 &, 000 \\
\hline & Trembling of hands & A7 &, 545 & 26,879 & 1 &, 000 \\
\hline & Generalized tremor or shaking & A8 & 678 & 115,213 & 1 &, 000 \\
\hline & Difficulty breathing & A9 &, 532 & 27,654 & 3 &, 000 \\
\hline & $\begin{array}{l}\text { Indigestion or discomfort in the } \\
\text { abdomen }\end{array}$ & A 10 &, 523 & 29,874 & 3 &, 000 \\
\hline & Facial Blush & A11 &, 598 & 115,897 & 1 &, 000 \\
\hline & Sweating & A12 &, 554 & 263,874 & 1 &, 000 \\
\hline \multirow{9}{*}{ Cognitive } & Heat sensation & A13 &, 565 & 24,654 & 1 &, 000 \\
\hline & Fear for the worst to happen & A14 & ,628 & 23,987 & 3 &, 000 \\
\hline & A feeling of instability & A15 &, 596 & 21,411 & 1 &, 000 \\
\hline & Feeling of being terrified & A16 &, 565 & 22,546 & 1 &, 000 \\
\hline & Feeling of choking & A17 &, 545 & 26,879 & 3 &, 000 \\
\hline & Fear of losing control & A18 &, 561 & 121,589 & 3 &, 000 \\
\hline & Fear of dying & A19 &, 532 & 120,541 & 1 &, 000 \\
\hline & Be afraid & $\mathrm{A} 20$ &, 534 & 107,687 & 3 &, 000 \\
\hline & Feeling going to faint & A21 &, 522 & 35,547 & 3 &, 000 \\
\hline
\end{tabular}

Source: authors' elaboration

In the construction of the SEM model was used the builder tool of the statistical software STATA 16. Was developed an analysis of main components of two constructs (physiological and cognitive). Figure 1, presents the Men's SEM model diagram:

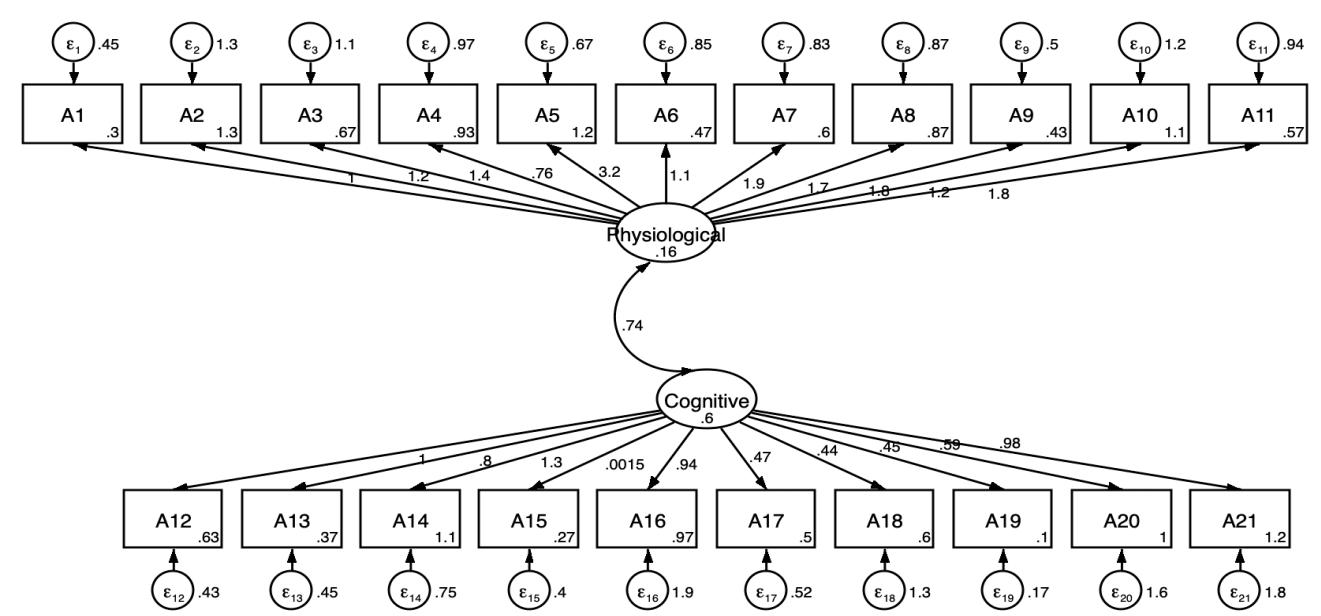


Figure 2, presents the women's SEM model diagram:

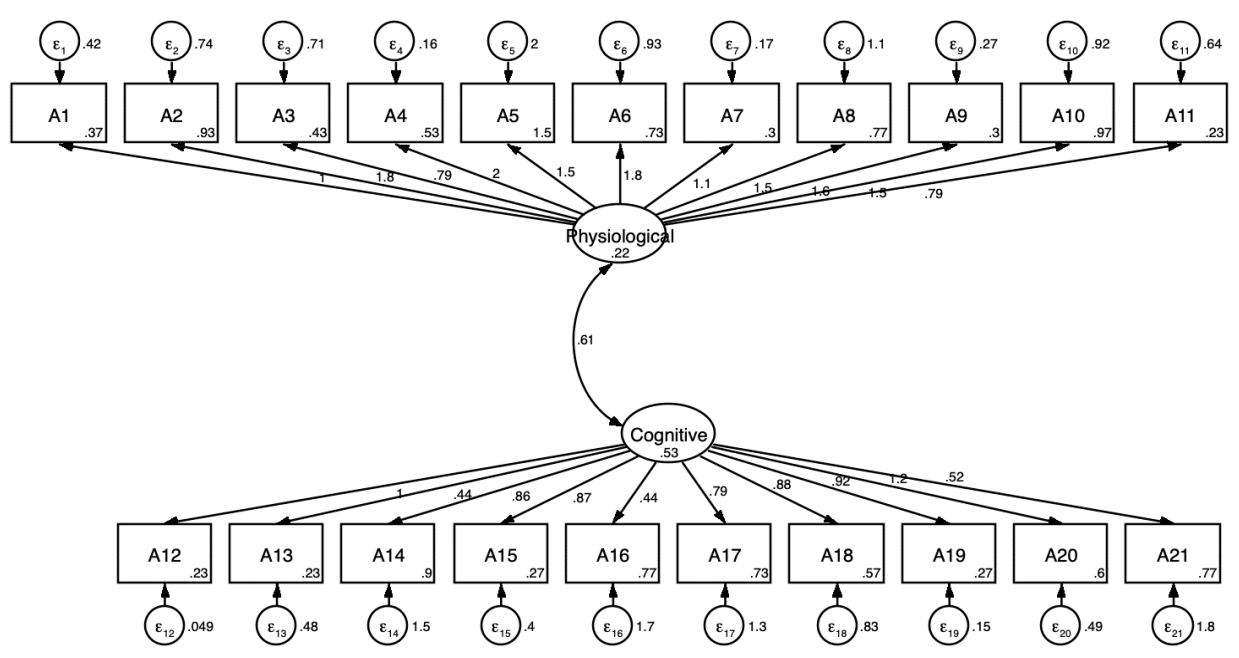

Table 5, presents the results of the goodness of fit test for men and women: For the men, the CFI and TLI, with values of 0.87 and 0.82 respectively, results that indicate a good fit. The CD was 0.78 , is approaching 1 that indicates a good fit. The lower and upper limits of the statistic RMSEA are 0.05 and 0.45 respectively, which indicates that the setting is good. For the women, the CFI and TLI, with values of 0.76 and 0.73 indicate a good fit. The Coefficient of determination was 0.77 , is approaching 1 that indicates a good fit. The lower and upper limits of the statistic RMSEA are 0.06 and 0.46 respectively, which indicates that the setting is good. In effect, the two SEMs models developed are properly adjusted to data.

Table 5. Statistics results Men and Women

\begin{tabular}{ccc}
\hline Statistic & Men & Women \\
\hline RMSEA & 0.058 & 0.047 \\
90 \% CI, lower & 0.061 & 0.053 \\
bound & 0.452 & 0.461 \\
Upper bound & 0.053 & 0.062 \\
AIC & 16614.313 & 15674.212 \\
BIC & 15684.132 & 14987.231 \\
CFI & 0.872 & 0.762 \\
TLI & 0.821 & 0.731 \\
SRMR & 0.164 & 0.154 \\
CD & 0.784 & 0.774 \\
\hline
\end{tabular}

Source: authors' elaboration

\section{Conclusions}

In the SEM models developed, we appreciate that all the signs of the coefficients of the slopes are positive, indicating a strong and direct correlation between the latent variables and constructs. For the men, on the latent variable physiological, the construct that has greater influence are the "Palpitations or tachycardia", whose coefficient is 3.2. For its part, the latent variable cognitive was affected in major part by the construct "A feeling of instability", with a coefficient of 1.3. There is a relationship between the latent variables physiological and cognition, which was estimated with a covariance of .74, indicating that both variables are correlated.

For the women, on the latent variable physiological, the construct that has greater influence are the "dizziness or vertigo", whose coefficient is 2.0. For its part, the cognitive variable was affected in major part by the construct "be afraid" with a coefficient of 1.2. The correlation of the physiological and cognition variables is direct, which was estimated with a covariance of .61. Mental health professionals working in SAC, should employ different types of treatment in men and women offenders to combat anxiety and have better results in the rehabilitation process. The main limitations of this research was the size of the sample. As future work it is proposed to develop new models of structural equations that analyze the influence of other types of mental illness other than 
anxiety (depression, paranoia, stress, anger, etc).

\section{References}

American Psychiatric Association. (2000). Diagnostic criteria from DSM-IV. American Psychiatric Pub. https://doi.org/10.4103/0019-5545.117131

Buckner, J. D., Lewis, E. M., Terlecki, M. A., Albery, I. P., \& Moss, A. C. (2019). Context-Specific Drinking and Social Anxiety: The Roles of Anticipatory Anxiety and Post-Event Processing. Addictive Behaviors, 106184. https://doi.org/10.1016/j.addbeh.2019.106184

Fox, E., Russo, R., \& Georgiou, G. A. (2005). Anxiety modulates the degree of attentive resources required to process emotional faces. Cognitive, Affective, \& Behavioral Neuroscience, 5(4), 396-404. https://doi.org/10.3758/CABN.5.4.396

Hirshfeld-Becker, D. R., Biederman, J., Henin, A., Faraone, S. V, Davis, S., Harrington, K., \& Rosenbaum, J. F. (2007). Behavioral inhibition in preschool children at risk is a specific predictor of middle childhood social anxiety: A five-year follow-up. Journal of Developmental \& Behavioral Pediatrics, 28(3), 225-233. https://doi.org/10.1097/01.DBP.0000268559.34463.d0

Hodgins, S., De Brito, S. A., Chhabra, P., \& Côté, G. (2010). Anxiety disorders among offenders with antisocial personality disorders: a distinct subtype? The Canadian Journal of Psychiatry, 55(12), 784-791. https://doi.org/10.1177/070674371005501206

Keen, D., Adams, D., Simpson, K., Den Houting, J., \& Roberts, J. (2019). Anxiety-related symptomatology in young children on the autism spectrum. Autism, 23(2), 350-358. https://doi.org/10.1177/1362361317734692

Kinner, S. A., Alati, R., Watt, K., Najman, J. M., Fowler, G., \& Green, D. (2005). Substance misuse, anxiety and depression and urgency of presentation to a public emergency department in Australia. Emergency Medicine Australasia, 17(4), 363-370. https://doi.org/10.1111/j.1742-6723.2005.00758.x

McCarthy, J., Chaplin, E., Forrester, A., Underwood, L., Hayward, H., Sabet, J., Murphy, D. (2019). Prisoners with neurodevelopmental difficulties: Vulnerabilities for mental illness and self-harm. Criminal Behaviour and Mental Health, 29(5-6), 308-320. https://doi.org/10.1002/cbm.2132

Mclntosh, A. R., \& Gonzalez - Lima, F. (1994). Structural equation modeling and its application to network analysis in functional brain imaging. Human Brain Mapping, 2(1-2), 2-22. https://doi.org/10.1002/hbm.460020104

Mullarkey, M. C., \& Schleider, J. L. (2020). Contributions of fixed mindsets and hopelessness to anxiety and depressive symptoms: A commonality analysis approach. Journal of Affective Disorders, 261, 245-252. https://doi.org/10.1016/j.jad.2019.10.023

Newby, J. M., Haskelberg, H., Hobbs, M. J., Mahoney, A. E. J., Mason, E., \& Andrews, G. (2019). The effectiveness of internet-delivered cognitive behavioural therapy for health anxiety in routine care. Journal of Affective Disorders. https://doi.org/10.1016/j.jad.2019.11.087

Price, L. R., Laird, A. R., Fox, P. T., \& Ingham, R. J. (2009). Modeling dynamic functional neuroimaging data using structural equation modeling. Structural Equation Modeling: A Multidisciplinary Journal, 16(1), 147-162. https://doi.org/10.1080/10705510802561402

Pruttiakaravanich, A., \& Songsiri, J. (2020). Convex formulation for regularized estimation of structural equation models. Signal Processing, 166, 107237. https://doi.org/10.1016/j.sigpro.2019.107237

Regehr, C., Carey, M., Wagner, S., Alden, L. E., Buys, N., Corneil, W.,White, N. (2019). Prevalence of PTSD, Depression and Anxiety Disorders in Correctional Officers: A Systematic Review. Corrections, 1-13. https://doi.org/10.1080/23774657.2019.1641765

Vertue, F. M. (2003). From adaptive emotion to dysfunction: An attachment perspective on social anxiety disorder. Personality and Social Psychology Review, 7(2), 170-191. https://doi.org/10.1207/S15327957PSPR0702_170-191

\section{Copyrights}

Copyright for this article is retained by the author(s), with first publication rights granted to the journal.

This is an open-access article distributed under the terms and conditions of the Creative Commons Attribution license (http://creativecommons.org/licenses/by/3.0/). 